\title{
Factors Related to LGBT Recognition for University Students and Employed Adults
}

\author{
Natsuko Kojima, Kyoko Asazawa \\ Division of Nursing, Faculty of Nursing, Tokyo Healthcare University, Tokyo, Japan \\ Email: 11DN001x2U-ts@slcn.ac.jp
}

How to cite this paper: Kojima, N. and Asazawa, K. (2020) Factors Related to LGBT Recognition for University Students and Employed Adults. Open Journal of Nursing, 10, 1038-1047.

https://doi.org/10.4236/ojn.2020.1011073

Received: October 10, 2020

Accepted: November 15, 2020

Published: November 18, 2020

Copyright $\odot 2020$ by author(s) and Scientific Research Publishing Inc. This work is licensed under the Creative Commons Attribution International License (CC BY 4.0).

http://creativecommons.org/licenses/by/4.0/

\begin{abstract}
Background: The aim of this study was to investigate Japanese students and employed adults' characteristic features, and sexual situation, and to find the correlated factors of lesbian, gay, bisexual, transgender (LGBT) recognition in order to obtain suggestions for improved relationships with sexual minorities in a diversifying society. Methods: This quantitative cross-sectional descriptive correlational study occurred during 2018 to 2019 when 2210 questionnaires were distributed to a purposive sample of eligible participants. A total of 1534 completed questionnaires (69.4\%) were returned, of which 1439 (65.1\%) were suitable for analyses. The survey included respondents' 1) characteristics, 2) sexual situation, and 3) LGBT recognition scale. Data were analyzed with descriptive statistics, factor analysis, reliability analysis, and structural equation modeling. SPSS ver. 26.0 (SPSS, Chicago, IL, USA) was used for data analysis at a 5\% significance level. Results: The LGBT recognition score was significantly affected by suffering from gender identity (standardized partial regression coefficient: $\beta=0.17, \mathrm{p}<0.001)$, age $(\beta=-0.19, \mathrm{p}$ $<0.001)$, learning about LGBT experience $(\beta=0.29, \mathrm{p}<0.001)$, experience of disclosure from LGBT person $(\beta=0.14, \mathrm{p}<0.001)$, sexual problems with intimate relationship $(\beta=0.07, p<0.001)$, and diversity penetration $(\beta=0.14$, $\mathrm{p}<0.05)$. Conclusions: Suffering from gender identity, learning about LGBT experience, experience of disclosure from LGBT person, sexual problem with intimate relationship, and diversity penetration had a positive effect, whereas age had negative effects on the LGBT recognition score.
\end{abstract}

\section{Keywords}

Sexual and Gender Minorities, Cross-Sectional Studies, Covariance Structure Analysis 


\section{Introduction}

In Japan, 8.9\% are classified as lesbian, gay, bisexual, transgender (LGBT), and the percentage of people in Japan who know the term LGBT is $68.5 \%$ (penetration rate), and it is increasing year by year [1]. Even so, LGBT people are prone to self-loathing and loneliness due to unconsciously discriminatory remarks, actions, and imposition of sexual orientation regardless of their gender identification [2]. According to Japanese research reports, LGBT people tend to have low self-esteem [3]. Studies from other countries found that LGBT people have a high suicide rate [4], and are prone to eating disorders [5]. Therefore, being poorly understood and in a minority, it is not surprising that LGBT people may have many health issues.

LGBT patients need competent nurses to support them; researchers found that education, training and practice, that included understanding LGBT issues, would improve the health outcomes of LGBT patients [6]. LGBT-focused education in medicine, dentistry, or nursing has been reported to help improve understanding and counseling skills for LGBT people [7]. It was also reported that the inclusion of LGBT health-related issues in the health curriculum and professional training for undergraduates was important [8] [9]. However, LGBT recognition is presumed to be low in Japan, where the penetration or diffusion of information and understanding of sexual minorities is lagging. A previous study by Asazawa et al. in 2019 established a valid and reliable scale for measuring LGBT recognition [9]. However, the target population was largely young women. Therefore, the purpose of this study was to build on the findings of Asazawa et al. and to investigate Japanese students and employed adults' characteristic features, and sexual situation, and to find the correlated factors of LGBT recognition in order to obtain suggestions for improving health care for sexual minorities in a diversifying society.

\section{Methods}

\subsection{Study Design}

This study was a descriptive quantitative cross-sectional questionnaire survey.

\subsection{Definition of Terms}

LGBT: Lesbian, Gay, Bisexual, and Transgender, an abbreviation that represents sexual and gender minorities.

Transgender: People who feel that they belong to the other sex, and not the sex they were born with, and who express this in their sexual behavior.

Diversity penetration: The extent to which the lives of minority populations are recognized in an economic market or population such as health care.

\subsection{Participants and Setting}

The participants were Japanese university undergraduate and graduate students and employed adults in a general company. There were two companies, a 
small-sized elderly care facility and a large publishing house. A majority of the employees of the elderly care facility were women, and a majority of employees of the publishing house were men. Data were collected by purposive sampling of the participants from a convenience sample of university students and employed adults in the Kanto district of Japan in which the head of the university and head of the companies agreed to cooperate with this study. Participants were selected because the head of the university and head of the companies agreed to cooperate in this study. The inclusion criteria were 1) undergraduate and graduate students or employed adults, and 2) could communicate in Japanese. The exclusion criterion was participants with severe psychiatric disorders.

\subsection{Procedures}

After obtaining permission from the department head of the university and head of the company, verbal and written information regarding the research project was provided to the participants. A self-administered questionnaire was designed to ask for a single answer anonymously. Submission of the completed questionnaire indicated consent. Employed adult participants were returned the completed questionnaire in a sealed envelope by post. Students returned the completed questionnaire in a sealed envelope either by post or by placing it in a collection box at the entrance lobby of the university. During the study period from June 2018 to June 2019, 2201 questionnaires were distributed to eligible participants. A total of 1534 (69.4\%) completed questionnaires were returned, of which 1439 (65.1\%) were suitable for analyses.

\subsection{Ethical Considerations}

The study was conducted after obtaining approval from the Ethics Committee for Epidemiological Studies at Tokyo Healthcare University. Following the Declaration of Helsinki, a written explanation regarding the study objectives, methods, protection of anonymity, and voluntary basis of participation was provided to each participant. The participants were also informed that the collected data would only be used for this study.

\subsection{Measures}

\subsubsection{Participants' Attributes}

The attributes of the participants surveyed included sex identified on family register, age, diversity penetration (Is diversity pervasive in your current environment? Select yes, no), education in middle and high school, significant medical history, and genital disease history (Table 1).

\subsubsection{Sexual Situation}

The participants' sexual situation included the following: Suffering from gender identity, Sexual problem with intimate partner/relationship (for all participants), Experience of disclosing from LGBT person, and experience of learning about LGBT (Table 2). 
Table 1. Demographic data of the participants $(\mathrm{N}=1439)$.

\begin{tabular}{|c|c|c|}
\hline Partisipants's sociodemographic characteristics & $\mathrm{N}$ & $\%$ \\
\hline \multicolumn{3}{|l|}{ Sexes on the family register } \\
\hline male & 221 & 15.4 \\
\hline female & 1218 & 84.6 \\
\hline \multicolumn{3}{|l|}{ Age (years) } \\
\hline $10 \mathrm{~s}$ & 532 & 37.0 \\
\hline $20 \mathrm{~s}$ & 577 & 40.1 \\
\hline $30 \mathrm{~s}$ & 69 & 4.8 \\
\hline $40 \mathrm{~s}$ & 102 & 7.1 \\
\hline $50 \mathrm{~s}$ & 104 & 7.2 \\
\hline $60 \mathrm{~s}$ & 30 & 2.1 \\
\hline over 70 & 25 & 1.7 \\
\hline \multicolumn{3}{|l|}{ Position } \\
\hline students & 1070 & 74.4 \\
\hline employed adults & 369 & 25.6 \\
\hline \multicolumn{3}{|l|}{ Diversity penetration } \\
\hline yes & 490 & 34.1 \\
\hline no & 949 & 65.9 \\
\hline \multicolumn{3}{|l|}{ Education in middle and high school } \\
\hline coeducation & 1102 & 76.6 \\
\hline single-sex & 337 & 23.4 \\
\hline \multicolumn{3}{|l|}{ Significant medical history } \\
\hline yes & 477 & 33.1 \\
\hline no & 962 & 66.9 \\
\hline \multicolumn{3}{|l|}{ Genital disease history } \\
\hline yes & 151 & 10.5 \\
\hline no & 1288 & 89.5 \\
\hline
\end{tabular}

Table 2. Participant's sexual situation $(\mathrm{N}=1439)$.

\begin{tabular}{lcc}
\hline \multirow{1}{*}{ Items } & Mean & SD \\
\cline { 2 - 3 } & $\mathrm{N}$ & $\%$ \\
\hline LGBT recognition scale & 40.6 & 5.5 \\
Suffering of gender identity & & \\
yes & 40 & 2.8 \\
no & 1399 & 97.2 \\
Sexual problem in close person & & \\
yes & 214 & 14.9 \\
no & 1225 & 85.1 \\
Experience of confession from LGBT & & \\
yes & 322 & 22.4 \\
no & 1117 & 77.6 \\
LGBT learning experience & & \\
yes & 846 & 58.8 \\
no & 593 & 41.2 \\
\hline
\end{tabular}




\subsubsection{LGBT Recognition Scale}

The level of LGBT recognition was evaluated using the original version of the LGBT recognition scale [9]. The 3 sub-scales of the LGBT recognition scale consisted of the Knowledge of LGBT, Understanding of LGBT, and Tolerance for LGBT. It has a total of 10 items, which are scored as follows: "Strongly Disagree" 1 point, "Disagree" 2 points, "Neutral" 3 points, "Agree" 4 points, and "Strongly Agree" 5 points. The score ranges from 10 to 50 points. The higher the score, the higher is the LGBT recognition. Asazawa et al., the developers of the LGBT recognition scale, had verified the reliability and validity [9].

\subsection{Statistical Analysis}

The software programs SPSS version 26.0 (SPSS, Chicago, IL, USA) and AMOS version 26.0 (IBM, Armonk, NY, USA) were used for the data analyses. The significance level was set at 5\%. The alpha coefficient and factor loadings were calculated to examine the reliability of the responses on scale. The covariance structure analysis was used. Attribute and gender status have been replaced with dummy variables to act as independent variables. A LGBT recognition prediction model was examined to determine whether these factors affected LGBT recognition in participants using structural equation modeling.

\section{Results}

During the study period, 2210 questionnaires were distributed to eligible participants. A total of 1534 completed questionnaires (69.4\%) were returned, of which 1439 were suitable for analyses. Therefore, the response rate was $65.1 \%$.

\subsection{Participants}

Table 1 shows the demographic characteristics of the participants. The gender identified on the family register was $15.4 \%$ for men and $84.6 \%$ for women, and $37.0 \%$ in their teens, $40.1 \%$ in their $20 \mathrm{~s}$, and $22.9 \% 30$ and above. There were 1070 students $(74.4 \%)$ and 369 employed adults (25.6\%).

A minority (34.1\%) reported the presence diversity penetration. Education in middle and high school was coeducation $76.6 \%$, and single-sex $23.4 \%$. Reporting significant medical history was $33.1 \%$ and $10.5 \%$ had genital disease history. Table 2 shows the participant's sexual situation. There were 40 participants $(2.8 \%)$ who suffered from gender identity, and 214 participants (14.9\%) had sexual problems with an intimate partner. There were 322 participants $(22.4 \%)$ who had the experience of disclosure by an LGBT person, and 846 participants (58.8\%) had learning experience about LGBT.

\subsection{Reliability and Validity of the Scales (Table 3)}

The factor structure was confirmed for each variable of LGBT recognition scale. The construct validity was confirmed by factor analysis using the maximum likelihood method and promax rotation. The results of the factor analysis yielded 
Table 3. Exploratory factor analysis of LGBT recognition scale $(\mathrm{N}=1439)$.

\begin{tabular}{|c|c|c|c|c|}
\hline \multirow{2}{*}{ No. } & \multirow{2}{*}{ Factor/items } & \multicolumn{3}{|c|}{ Factor loading } \\
\hline & & Factor 1 & Factor 2 & Factor 3 \\
\hline & \multicolumn{4}{|l|}{ Factor 1: Knowledge of LGBT Cronbach's $\alpha=0.83$} \\
\hline 2 & I have an understanding of homosexuals and bisexuals. & 0.96 & 0.00 & -0.02 \\
\hline 1 & I have an understanding of gender identity disorder. & 0.94 & 0.01 & -0.02 \\
\hline \multirow[t]{2}{*}{3} & I want to find out more about LGBT myself. & 0.35 & 0.15 & 0.06 \\
\hline & \multicolumn{3}{|l|}{ Factor 2: Understanding of LGBT Cronbach's $\alpha=0.79$} & \\
\hline 4 & I feel that "homosexuals and bisexuals have difficulty living". & -0.02 & 0.95 & -0.02 \\
\hline 6 & I feel that "there is social criticism and pressure on LGBT". & 0.03 & 0.91 & -0.03 \\
\hline \multirow[t]{2}{*}{5} & I feel that "people with gender identity disorder have difficulty living". & 0.00 & 0.53 & 0.06 \\
\hline & \multicolumn{4}{|l|}{ Factor 3: Tolerance for LGBT Cronbach's $\alpha=0.82$} \\
\hline 7 & I accept family and friends even if they are homosexual or bisexual. & -0.08 & -0.03 & 0.94 \\
\hline 9 & Being homosexual or bisexual is a matter of personal choice. & -0.05 & 0.00 & 0.92 \\
\hline 10 & I refrain from discriminatory language against LGBT parties. & 0.10 & 0.12 & 0.46 \\
\hline \multirow[t]{5}{*}{8} & I accept family and friends even if they are transgender. & 0.22 & 0.12 & 0.40 \\
\hline & Rotation sums of squared loadings & 3.12 & 2.37 & 2.96 \\
\hline & \multirow[t]{3}{*}{ Factor correlation matrix } & 1 & & \\
\hline & & 0.27 & 1 & \\
\hline & & 0.59 & 0.23 & 1 \\
\hline
\end{tabular}

Exploratory factor analysis, Maximum likelihood method, promax rotation; Cumulative contribution ratio 63.2\%; Cronbach's alpha for the total score was 0.83 .

a factor loading of 0.35 or more for all the items, and the contribution rate of LGBT recognition scale was $63.2 \%$. The reliability of the scale was reconfirmed using the Cronbach's a coefficient with a value of 0.83 . Accordingly, reliability and validity were reconfirmed for LGBT recognition. Based on the above validity and reliability examination, it was reconfirmed that the LGBT recognition scale was appropriate, thus the 10 original items were accepted for this study. The total score was calculated and the average score of LGBT recognition scale score for the participants was $40.6 \pm 5.5$ points.

\subsection{LGBT Recognition Prediction Model}

A LGBT recognition prediction model was created using structural equation modeling. The latent variables selected were nine factors: age, sex, diversity penetration, significant medical history, genital disease history, suffering from gender identity, sexual problem with intimate partner, experience of disclosure from LGBT person, and learning about LGBT experience. The sex, significant medical history, and genital disease history among the observed variables were excluded from the model because they had no significant path coefficient. Thus, the LGBT recognition value for the Japanese students and employed adult-related 
model used in this study can reliably explain the relationships among the age, diversity penetration, suffering from gender identity, sexual problem with intimate partner, experience of disclosure from an LGBT person, and learning experience about LGBT. There were three questions (Q3, Q4, and Q5) in the LGBT recognition scale among the latent variables that were excluded from the model because they had no significant path coefficient. The measurement model was then retested resulting in a better model fit index. Drawing the partial correlation coefficient for the same error variables created the final model. The final values were as follows: $\mathrm{GFI}=0.978$; $\mathrm{AGFI}=0.965$; $\mathrm{CFI}=0.979$, $\mathrm{RMSEA}=0.044$, AIC $=281.3$, chi-square score $=213.3$, degree of freedom $=57$, and chi-square $/$ degree of freedom ratio $=3.742$. The final model is shown in Figure 1 . The standardized estimates were all significant at the $5 \%$ level. The fit indices demonstrated an adequate fit of the model to the data. The LGBT recognition score was significantly affected by suffering from gender identity (standardized partial regression coefficient: $\beta=0.17, \mathrm{p}<0.001)$, age $(\beta=-0.19, \mathrm{p}<0.001)$, learning experience about LGBT $(\beta=0.29, \mathrm{p}<0.001)$, experience of disclosure from LGBT ( $\beta$ $=0.14, \mathrm{p}<0.001)$, sexual problem with intimate partner $(\beta=0.07, \mathrm{p}<0.001)$, and diversity penetration $(\beta=0.14, \mathrm{p}<0.05)$. Therefore, suffering from gender identity, learning experience about LGBT, experience of disclosure from an LGBT person, sexual problem with intimate partner, and diversity penetration had a positive effect, whereas age had a negative effect on the LGBT recognition score.

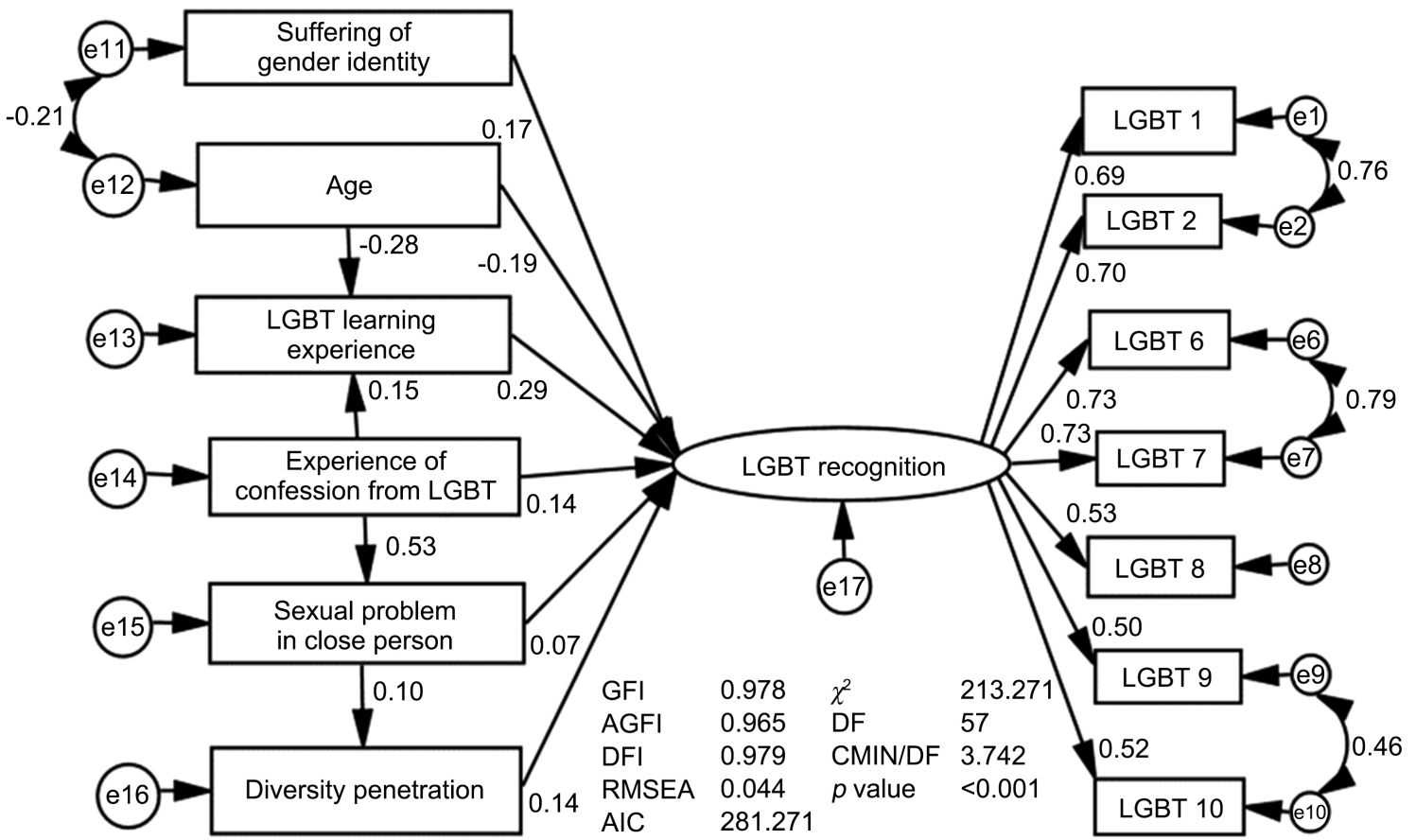

Figure 1. The LGBT recognition prediction model for Japanese students and employed adults $(\mathrm{N}=1439)$. ${ }^{\star} \mathrm{GFI}=$ Goodness of Fit Index, AGFI = Adjusted Goodness of Fit Index, CFI = comparative fit index, RAMSEA $=$ Root Mean Square Error of Approximation, AIC = Akaike's Information Criterion, $\chi^{2}=$ chi-square value, $\mathrm{DF}=\mathrm{degrees}$ of freedom, CMIN/DF = chi-squared/degree of freedom. 


\section{Discussion}

\subsection{Participants}

This quantitative cross-sectional survey study investigated Japanese students and employed adults' characteristic features, and sexual situations, and to find the correlated factors of LGBT recognition in order to obtain suggestions for improving health care providers' relationships with sexual minorities. Since many participants were selected from a university setting, the participants were young students in their teens and 20s, the majority of respondents were women. Because many of the participants were young, the penetration of diversity learning was high at $34 \%$, and the experience of learning about LGBT was $58 \%$, while $80 \%$ of Japanese feel the need to increase diversity, only $10 \%-45 \%$ of companies are working all on diversity, not just LGBT [10]. According to Okumura, 33\% of university students had learning experiences about LGBT [11]. Compared to these reports, participants in this study were considered to be more knowledgeable and informed about LGBT. The percentage of people with suffering from gender identity was $2.8 \%$, which was considerably lower than $8.9 \%$ in the Dentsu survey [1]. However, $14.9 \%$ had a sexual problem with intimate partner, and $22 \%$ had an Experience of disclosure from an LGBT person. Participants were aware that others besides themselves had sexual problems. It was thought that the participants were very sensitive and easily recognized the situation of others.

\subsection{Need for LGBT Education}

Six factors were associated with LGBT recognition: age, diversity penetration, suffering from gender identity, Sexual problem with intimate relationship, experience of disclosure from an LGBT person, and LGBT learning experience. High LGBT recognition leads to an understanding of sexual minorities.

LGBT recognition is important for an environment where people with sexual minorities can live comfortably. Therefore, in order to create a society where sexual minorities can live comfortably, it is necessary to 1) create an atmosphere that makes it easy to discuss sexual issues with others and especially their health care providers, 2) set up an environment that makes it easy to disclose about sexual orientation, and 3) LGBT learning experience. Diversity education and initiatives in Japan are mainly about women, the elderly, and people with disabilities, and there are only a few about sexual minorities [12]. It is important to create a social environment where a variety of minorities such as race and sexual orientation can live comfortably [13]. In order to create a comfortable society particularly within the health care system with less discrimination, we would like to implement an LGBT learning program for people of all ages and genders and strive to understand each other. Diversity and inclusion education is more necessary for Japanese educational institutions.

\section{Conclusion}

Predictors of the LGBT recognition value for the Japanese students and em- 
ployed adults were age, diversity penetration, suffering from gender identity, sexual problem with intimate relationship, experience of disclosure from an LGBT person, and LGBT learning experience. Results suggested that LGBT learning experience is necessary for Japanese students and employed adults in order to create an environment with high LGBT recognition and diversity.

\section{Acknowledgements}

The authors would like to thank all the participants, as well as the facility staff for their valuable contributions in this study.

\section{Conflicts of Interest}

The authors declare no conflicts of interest regarding the publication of this paper.

\section{References}

[1] DENTSU Diversity LAB (2018) LGBT Survey 2018. https://dentsu-ho.com/articles/6542

[2] Ministry of Health, Labor and Welfare (2017) Suicide Comprehensive Measures Charter.

https://www.mhlw.go.jp/stf/seisakunitsuite/bunya/hukushi kaigo/seikatsuhogo/jisa tsu/taikou h290725.html

[3] Shinohara, Y. and Nakatsuka, M. (2018) Descriptive Study of Gender Identity in Japanese Individuals with Male-to-Female Gender Identity Disorder. Acta Medica Okayama, 72, 143-151. https://pubmed.ncbi.nlm.nih.gov/29674763/

[4] Peter, T., Edkins, T., Watson, R., Adjei, J., Homma, Y. and Saewyc, E. (2017) Trends in Suicidality among Sexual Minority and Heterosexual Students in a Canadian Population-Based Cohort Study. Psychology of Sexual Orientation and Gender Diversity, 4, 115-123. https://pubmed.ncbi.nlm.nih.gov/29326961/

[5] Watson, R.J., Adjei, J., Saewyc, E., Homma, Y. and Goodenow, C. (2017) Trends and Disparities in Disordered Eating among Heterosexual and Sexual Minority Adolescents. International Journal of Eating Disorders, 50, 22-31. https://pubmed.ncbi.nlm.nih.gov/27425253/

[6] Cloyes, K.G., Hull, W. and Davis, A. (2018) Palliative and End-of-Life Care for Lesbian, Gay, Bisexual, and Transgender (LGBT) Cancer Patients and Their Caregivers. Seminars in Oncology Nursing, 34, 60-71. https://pubmed.ncbi.nlm.nih.gov/29306523/

[7] Taylor, A.K., Condry, H. and Cahill, D. (2018) Implementation of Teaching on LGBT Health Care. Clinical Teacher, 15, 141-144. https://pubmed.ncbi.nlm.nih.gov/28401669/

[8] McCann, E. and Brown, M. (2018) The Inclusion of LGBT+ Health Issues within Undergraduate Healthcare Education and Professional Training Programmes: A Systematic Review. Nurse Education Today, 64, 204-214. https://pubmed.ncbi.nlm.nih.gov/29510349/

[9] Asazawa, K., Inamoto, A., Suzuki, M., et al. (2019) Predictors of LGBT Recognition by Health Sciences University Students in Japan. Open Journal of Nursing, 9, 481-493. https://www.scirp.org/journal/paperinformation.aspx?paperid $=92410$ 
[10] Yoshida, H. and Yoshihasi, S. (2018) What Is Diversity? From the Results of a Questionnaire Survey Conducted by the Diversity Promotion Committee. Journal of the Atomic Energy Society of Japan, 60, 303-306.

https://www.jstage.jst.go.jp/article/jaesjb/60/5/60 303/ pdf/-char/ja

[11] Okumura, R. and Kase, S. (2017) Research on the Knowledge, Understanding and Learning Experience of LGBT among the Students in the Teacher Training University: Through a Questionnaire Survey at T-University. Bulletin of Tokyo Gakugei University. Educational Sciences, 68, 1-10.

https://ci.nii.ac.jp/naid/120006509443

[12] Hotta, A.A. (2015) Study of Future Research of Diversity Management in Japan. Hiroshima University Management Review, No. 16, 17-29. https://ci.nii.ac.jp/naid/120005575288/

[13] Ishihara, H. (2017) A Local Perspective on Sexual Minorities in Japan: Regional Comparisons Using the World Value Surveys. The Meiji Gakuin Sociology and Social Welfare Review, 147, 1-20. https://ci.nii.ac.jp/naid/120006240534 